\title{
Fabrication of Aluminum Foams with Small Pore Size by Melt Foaming Method
}

\author{
YING CHENG, YANXIANG LI, XIANG CHEN, TONG SHI, ZHIYONG LIU, \\ and NINGZHEN WANG
}

\begin{abstract}
This article introduces an improvement to the fabrication of aluminum foams with small pore size by melt foaming method. Before added to the melt, the foaming agent (titanium hydride) was pretreated in two steps. It firstly went through the traditional pre-oxidation treatment, which delayed the decomposition of titanium hydride and made sure the dispersion stage was controllable. Then such pre-oxidized titanium hydride powder was mixed with copper powder in a planetary ball mill. This treatment can not only increase the number of foaming agent particles and make them easier to disperse in the melt, which helps to increase the number of pores, but also reduce the amount of hydrogen released in the foaming stage. Therefore, the pore size could be decreased. Using such a ball-milled foaming agent in melt foaming method, aluminum foams with small pore size (average size of $1.6 \mathrm{~mm}$ ) were successfully fabricated.
\end{abstract}

DOI: $10.1007 / \mathrm{s} 11663-016-0815-6$

(C) The Minerals, Metals \& Materials Society and ASM International 2016

\section{INTRODUCTION}

Closed-Cell aluminum foams, in which pores exist separately, have many unique properties compared to traditional dense metallic materials due to the existence of pore structure: light-weight, considerable energy absorption and sound insulation performance, good electromagnetic shielding ability, low thermal conductivity, etc. ${ }^{[1-6]}$ These excellent properties allow aluminum foams to be used in many application fields. ${ }^{[7-9]}$

Among various manufacturing methods, melt foaming method is one of the most widely used one. ${ }^{[8]}$ It has a simple procedure and is easy to fabricate large foam blocks, which makes it the most promising method for commercial production of aluminum foams. ${ }^{[10]}$ Currently, typical pore size of aluminum foams made by melt foaming method is 3 to $6 \mathrm{~mm} \cdot{ }^{[11]}$ Unfortunately, with such range of pore size, the performance of the foam products is not good enough. On the one hand, its secondary processing properties are poor. ${ }^{[12]}$ On the other hand, its compressive strength and energy absorption still have the potential to be developed better. ${ }^{[10]}$ Due to the existence of such problems, the development and applications of melt foaming method along with its products are limited.

One promising way to solve these problems is to decrease the pore size. Recent research has shown that the decrease

YING CHENG, NINGZHEN WANG, TONG SHI, ZHIYONG LIU are with the School of Materials Science and Engineering, Tsinghua University, Beijing 100084, P.R. China. YANXIANG LI and XIANG CHEN are with the School of Materials Science and Engineering, Tsinghua University, and the Key Laboratory for Advanced Materials Processing Technology, MOE, Beijing, P.R.

China. Contact e-mail: yanxiang@tsinghua.edu.cn

Manuscript submitted April 30, 2016.

Article published online January 3, 2017. of the pore size can improve the performance of aluminum foams. Babcsan et al.$^{[13,14]}$ found that when the pore size is decreased to around $1 \mathrm{~mm}$, the foams are stable enough to be re-melted and cast into complex shapes. They can also be roll-casted into thin plates and welded with aluminum plate. Yi et al. ${ }^{[15]}$ and Xiaoqing et al. ${ }^{[16]}$ compared the compressive performance of aluminum foams with different pore sizes and porosity and observed that compressive strength showed an increase when the pore size and porosity decreased to below $2 \mathrm{~mm}$ and 70 pct, respectively. It can be seen from references 13 to 16 that foams with small pore size (below $2 \mathrm{~mm}$ ) and low porosity (60 to 70 pct) will have a higher foam stability, which means more uniform pore structure, less defects and more secondary forming possibility. In addition, its compressive strength and energy absorption capacity will be improved. All these improvements contribute to the further development and application of melt foaming method and its products. Therefore, reduction of pore size in aluminum foams is an important research area.

So far, research on fabrication of aluminum foams with small pore size by melt foaming method is little. ${ }^{[17-20]} \mathrm{In}$ these studies, an essential requirement to obtain foams with a pore size of around $1 \mathrm{~mm}$ is that the foaming time must be short and the melt should be solidified before the pores growing large. However, due to the low thermal conductivity of aluminum foams, ${ }^{[5]}$ it is very difficult to realize rapid solidification of the entire foam at the same time. If the solidification process starts before the foaming process is completed, the difference in solidification time of outer and inner areas can be very big (especially for large foam blocks). So the difference of pore growth time can be big as well, which leads to an inhomogeneous pore size distribution. ${ }^{[16,19,20]}$

In this study, a modification of the melt foaming method was introduced to fabricate aluminum foams with small pore size and the solidification process was 
started after the foaming process was completed to avoid inhomogeneous pore size distribution. In the pretreatment process of the foaming agent (titanium hydride), besides traditional pre-oxidation treatment, ${ }^{[21]}$ the pre-oxidized titanium hydride was mixed with copper powder by ball milling before adding to the melt to make it easier to disperse and thus could reduce the particle aggregation in the melt. The result indicates that ball milling treatment can obviously reduce the pore size and the reasons of such improvement are discussed.

\section{EXPERIMENTAL PROCEDURE}

\section{A. Materials}

The primary raw materials in our experiments were industrial pure aluminum ingot (matrix material, provided by Xinjiang Sixth Aluminum Co., Ltd., purity of 99.7 pct), Calcium granules (thickening agent, provided by Linzhou Hongrui Metal Material Processing Co., Ltd., average size of 2 to $4 \mathrm{~mm}$, purity $>98 \mathrm{pct}$ ), Titanium hydride powder (foaming agent, provided by Baoji Yuanheng Metals Products Co., Ltd., -300 mesh, purity $>99.4$ pct) and Copper powder (dispersion agent, provided by Tianjin Yongda Chemical Reagent Co., Ltd., -200 mesh, analytical purity)

\section{B. Pretreatment of Titanium Hydride}

Titanium hydride powder was pretreated in two steps: it was firstly pre-oxidized at $773 \mathrm{~K}\left(500{ }^{\circ} \mathrm{C}\right)$ for 2 hours in air in a chamber furnace. ${ }^{[22]}$ Then the pre-oxidized titanium hydride powder was mixed with copper powder in a planetary ball mill. Both the jars and balls are made of stainless steel and balls of two sizes (10 and $5 \mathrm{~mm}$ ) were used to obtain a better mixing effect. In the milling process, weight ratio of ball to powder and milling rate were fixed. Meanwhile, weight ratio of titanium hydride powder to copper powder and milling time were varied to find out the proper milling parameters. Detailed parameters are listed in Table I.

\section{Fabrication of Aluminum Foams}

Aluminum foams were fabricated by melt foaming method. ${ }^{[23-25]}$ The main fabrication process included the following steps: (1) Pure aluminum ingot (about $3 \mathrm{~kg}$ ) was melted in an electrical resistance furnace; (2) Calcium granules ( $3 \mathrm{wt} \mathrm{pct}$ ) were added into the melt at $953 \mathrm{~K}\left(680{ }^{\circ} \mathrm{C}\right)$ and stirred for 8 to 10 minutes to increase the melt viscosity; (3) After the temperature was reduced to $933 \mathrm{~K}\left(660{ }^{\circ} \mathrm{C}\right)$, titanium hydride was added into the melt and stirred for 3 to 5 minutes (both
Table II. Titanium Hydride Forms and Amount Used in Fabrication Process

\begin{tabular}{llll}
\hline Form & unmilled & unmilled & milled \\
Amount & $0.3 \mathrm{wt} \mathrm{pct}$ & $0.5 \mathrm{wt} \mathrm{pct}$ & $0.5 \mathrm{wt} \mathrm{pct}$ \\
\hline
\end{tabular}

unmilled and milled titanium hydride were used, as listed in Table II, unmilled form means titanium hydride was added directly, milled form means titanium hydride was added after mixed with copper powder); (4) After the titanium hydride dispersion stage, the temperature of melt was maintained to allow foaming process to take place; (5) After the foaming process was completed (for about 5 minutes), the foam was removed from the furnace and cooled in air.

\section{Characterization Method}

The morphology of powders were observed using a field emission scanning electron microscope (FESEM) (Zeiss MERLIN-VP-COMPACT) equipped with energy-dispersive X-ray spectroscope (EDS) analyzer (Oxford INCA). The phases present were determined by $\mathrm{X}$-ray diffraction (XRD) analysis on a D8-Advance diffractometer $(\mathrm{Cu} \mathrm{K} \alpha, \lambda=0.154 \mathrm{~nm})$.

Image-Pro Plus 6.0 was used to calculate pore size distribution and average value. The porosity of foams $(P)$ was calculated according to Eq. [1] and [2] (where $\rho^{*}$, $M$ and $V$ are the foam's apparent density, mass and volume respectively, $\rho_{s}\left(\approx 2.7 \mathrm{~g} / \mathrm{cm}^{3}\right)$ is the matrix metal's density, $P$ is the foam's porosity.

$$
\begin{gathered}
\rho^{*}=\frac{M}{V} \\
P=\left(1-\frac{\rho^{*}}{\rho_{s}}\right) \times 100 \mathrm{pct}
\end{gathered}
$$

\section{RESULTS AND DISCUSSION}

\section{A. Foaming Results}

Figure 1 shows the porous structure of aluminum foams fabricated by different adding forms and amounts of titanium hydride. The parameters of ball milling process used in Figure 1(c) through (f) are as follows: weight ratio of titanium hydride powder to copper powder was $1: 1$, weight ratio of ball to powder was $3: 1$, milling rate was $250 \mathrm{r} / \mathrm{min}$ and milling time was 4 hours.

Table I. Parameters Used in Ball Milling

\begin{tabular}{lll}
\hline Fixed Parameters & Weight Ratio of Ball to Powder & Milling Rate \\
& $3: 1$ & $250 \mathrm{r} / \mathrm{minutes}$ \\
Variable parameters & weight ratio of titanium hydride powder to copper powder & milling time \\
& $1: 1,1: 2,1: 4$ & $2,4,6 \mathrm{~h}$ \\
\hline
\end{tabular}



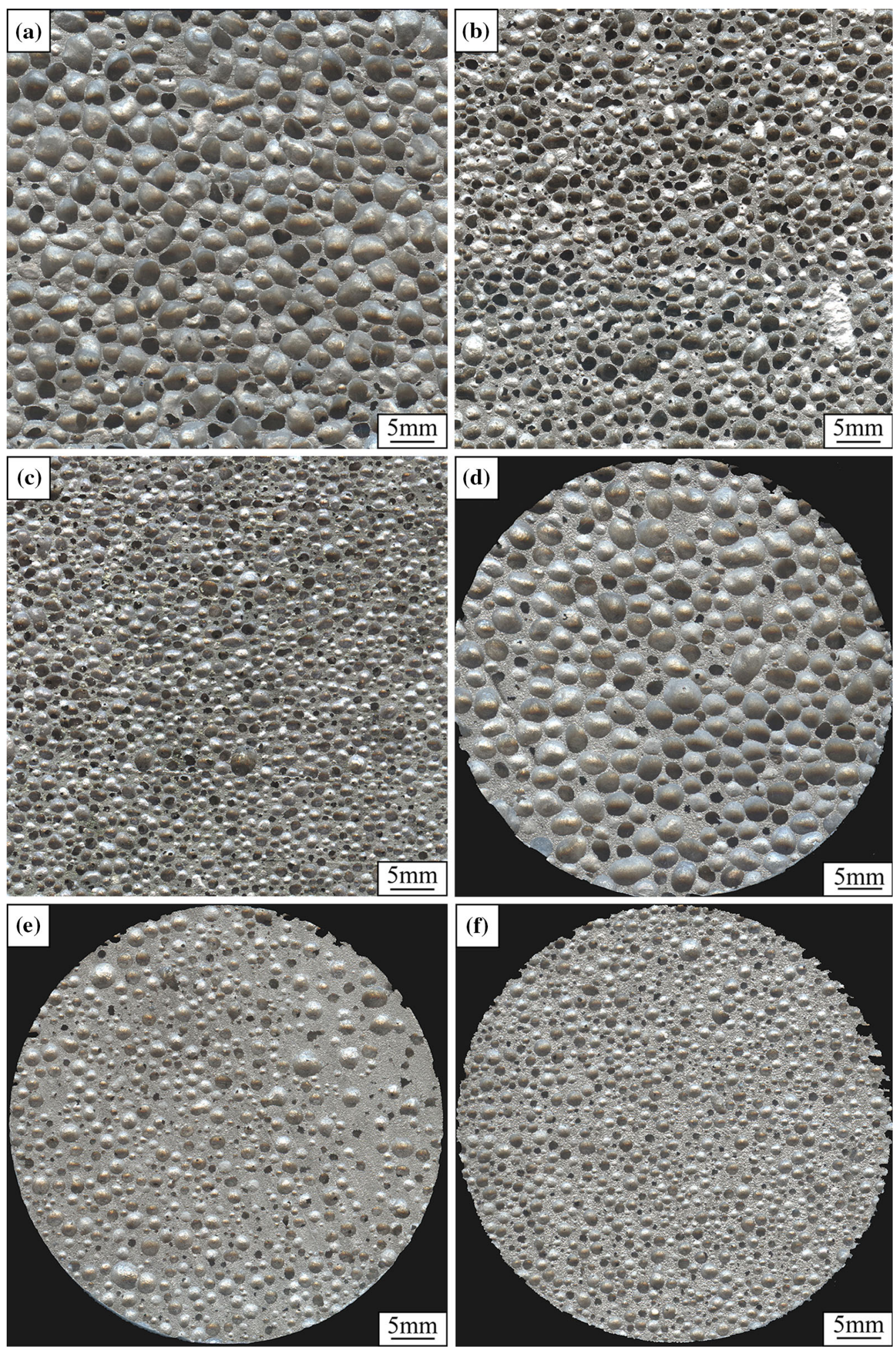

Fig. 1-Porous structure of aluminum foams fabricated by different forms and amounts of titanium hydride: ( $a$ through $c)$ longitudinal; $(d$ through $f$ ) transverse; $(a)$ and $(d)$ unmilled, $0.5 \mathrm{wt}$ pct; $(b)$ and $(e)$ unmilled, $0.3 \mathrm{wt}$ pct; $(c)$ and $(f)$ milled, 0.5 wt pct. 


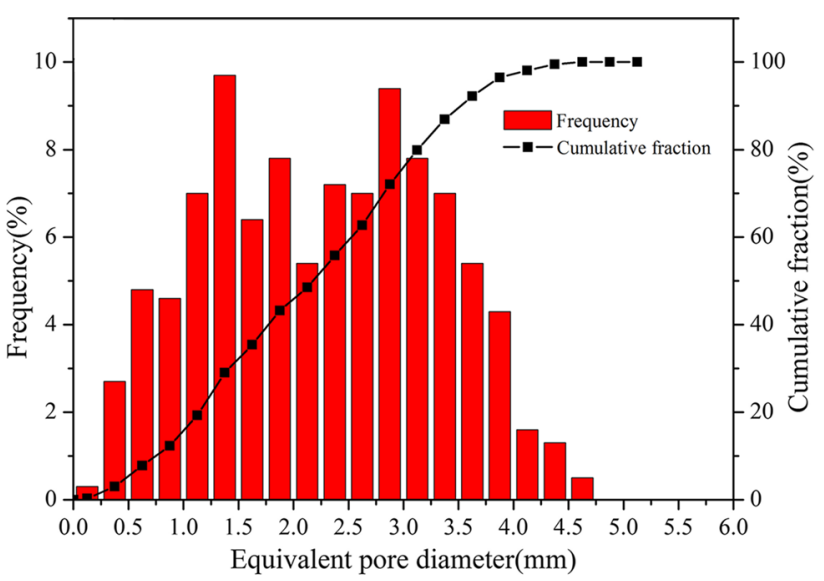

(a)

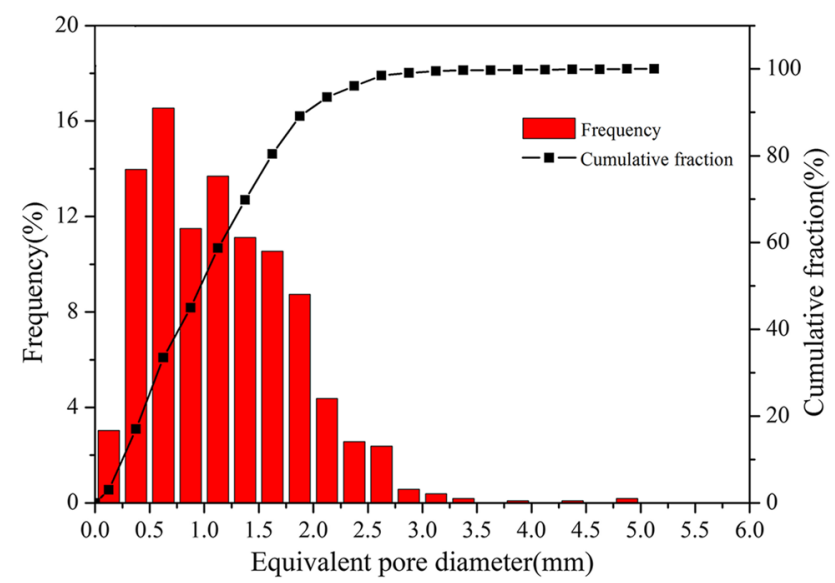

(b)

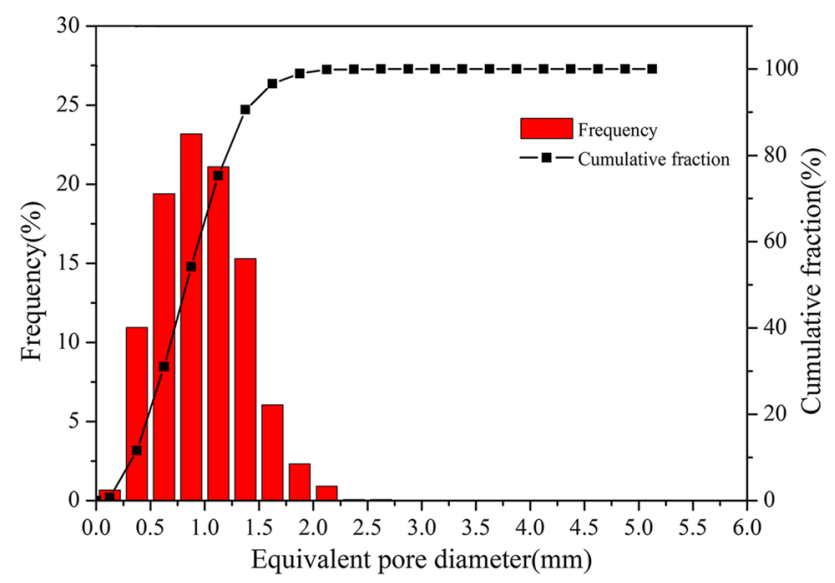

(c)

Fig. 2-Pore size distribution on the section of aluminum foams fabricated by different forms and amounts of titanium hydride: $(a)$ unmilled, 0.5 wt pct; $(b)$ unmilled, $0.3 \mathrm{wt}$ pct; $(c)$ milled, $0.5 \mathrm{wt}$ pct.
Figure 2 shows the pore size distribution of aluminum foams in Figure 1. The corresponding pore structure parameters are listed in Table III, where $P$ is the porosity, $d_{s}$ is the $2 \mathrm{D}$ equivalent average diameter of pores(calculated by Image-Pro Plus 6.0), $d_{r}$ is the $3 \mathrm{D}$ equivalent average diameter of pores, $N$ represents the pore number per unit area.

According to the statistical analysis, the relationship between $d_{s}$ and $d_{r}$ can be described using Eq. [3] ${ }^{[26]}$.

$$
d_{r}=d_{s} / 0.616
$$

Based on the above foaming results, it can be inferred that small average pore size and uniform pore size distribution can be obtained when titanium hydride is added to the melt in milled form. By using titanium hydride in milled form, aluminum foams with $1.6 \mathrm{~mm}$ average pore size, 64 pct porosity and a uniform pore structure were successfully fabricated. It should be noted that this kind of small pore size aluminum foams can be obtained after the foaming process is completed, which means a short foaming time and rapid solidification are no longer needed. Therefore, the whole fabrication process will be more controllable and a uniform pore size distribution can be ensured.

\section{B. The Role of Ball Milling Treatment}

In melt foaming method, pores are likely to form around titanium hydride particles. ${ }^{[27]}$ Thus, the number of titanium hydride particles in the melt and its dispersion will directly determine the number of pores and final pore size. Figure 3 schematically shows how the dispersion of titanium hydride particles influences the final pore size. When aggregation exists, not all titanium hydride particles can act as pore nucleuses and growth of each bubble is driven by gas released from several particles, which results in less pores with larger size. In the absence of aggregation (ideal condition), each titanium hydride particle may act as a pore nucleus and the growth of each bubble is driven by gas released from individual particle, thus resulting in more pores with smaller size.

Hence, the key to obtain small pore size is to increase the number of titanium hydride particles and ensure they can disperse uniformly in the melt (i.e., aggregation among particles are as small as possible). Unfortunately, the dispersion of titanium hydride particles in aluminum melt is very difficult due to the particularity of foaming process. On the one hand, titanium hydride particles are poorly wetted by aluminum melt ${ }^{[28]}$; On the other hand, the time for dispersion is short due to the restriction of titanium hydride's decomposition. Although pre-oxidation treatment can delay the decomposition and give

Table III. Pore Structure Parameters of Aluminum Foams Shown in Fig. 1

\begin{tabular}{lcccc}
\hline Titanium Hydride Forms and Amount & $P($ Pct $)$ & $d_{s}(\mathrm{~mm})$ & $d_{r}(\mathrm{~mm})$ & $N\left(\mathrm{per} \mathrm{cm}^{2}\right)$ \\
\hline (a) and (d) unmilled, 0.5 wt pct & 79.4 & 2.3 & 3.7 & 15 \\
(b) and (e) unmilled, 0.3 wt pct & 64.0 & 1.3 & 2.1 & 42 \\
(c)and (f) milled, 0.5 wt pct & 64.0 & 1.0 & 1.6 & 65 \\
\hline
\end{tabular}



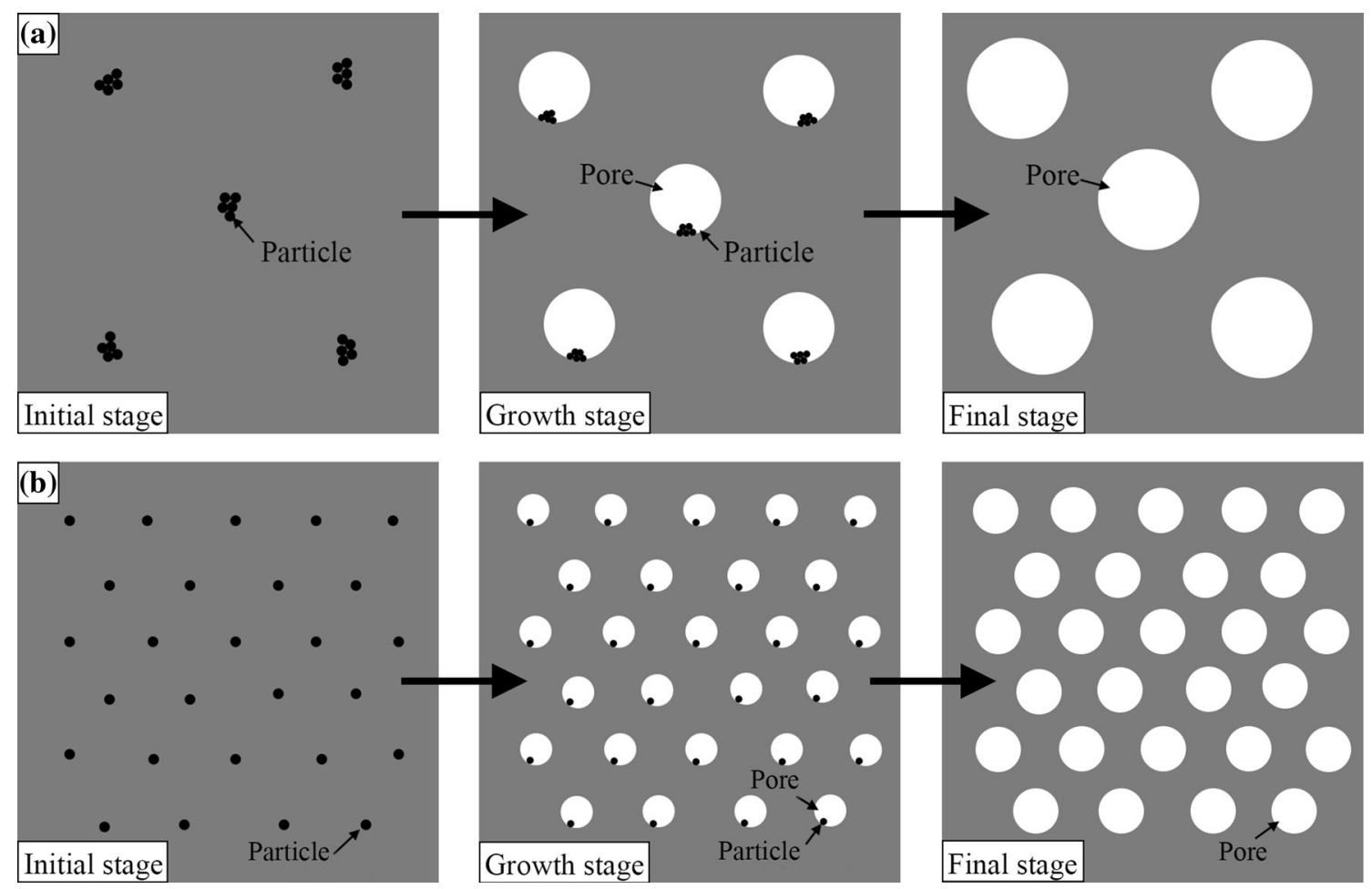

Fig. 3-Schematic diagram of the influence of particle dispersion on the final pore size: $(a)$ aggregation exists among particles; $(b)$ no aggregation among particles.

more time for dispersion, the wettability problem is still hard to solve. Thus the particles are easy to aggregate in the melt and small pore size is difficult to be obtained (see Figure 3(a)).

In order to improve the wettability and make titanium hydride particles easier to disperse in the melt with less aggregation, ball milling process was employed. Ball milling is a very effective way to eliminate the aggregation among particles and has already been successfully used to facilitate the dispersion of nano particles in the metal melt. ${ }^{[29,30]}$ In our study, copper powder was chosen to mix with titanium hydride powder due to the following reasons: (1) The wettability between copper and aluminum is good ${ }^{[31]}$; (2) Copper powder is less easy to be contaminated by oxidation compared to aluminum powder; (3) the addition of copper will contribute to the formation of a $\mathrm{Al}_{2} \mathrm{Cu}$ solid solution according to $\mathrm{Al}-\mathrm{Cu}$ phase diagram, which can act as a strengthening phase to improve the mechanical property of foams. ${ }^{[32]}$

Figure 4 shows the morphology of titanium hydride and copper powder mixture after different milling time (weight ratio of titanium hydride powder to copper powder was 1:1).

The mixture of titanium hydride and copper powder can be seen as a ductile-brittle system during ball milling process. ${ }^{[33]}$ In the first stage, ductile copper particles underwent deformation and got flattened; in contrast, brittle titanium hydride particles underwent fragmentation and got fractured. Subsequently, the flattened copper particles started to weld together and the fractured titanium hydride particles tended to become occluded by the welded copper particles and get embedded in it. After the repeated welding, fracturing and re-welding process of the powder mixture, the composite particles in which fractured titanium hydride particles were dispersed by welded copper particles can be formed in the final stage. Figure 5 schematically shows the morphology changes of titanium hydride and copper powder during ball milling process. The existence of the composite particles mentioned above is shown in Figure 4, where the distribution of titanium hydride and copper particles is determined by EDS results.

After ball milling, the copper particles which have a good wettability with aluminum can act as a carrier to send titanium hydride particles into the melt and make them easier to be wetted by aluminum melt. Meanwhile, titanium hydride particles were pre-dispersed in copper matrix, thus makes it easier to disperse in the melt with less aggregation. Furthermore, the fracture process of titanium hydride will increase the number of particles. All these improvements will contribute to increasing the number of pores, thus decreasing the pore size. 

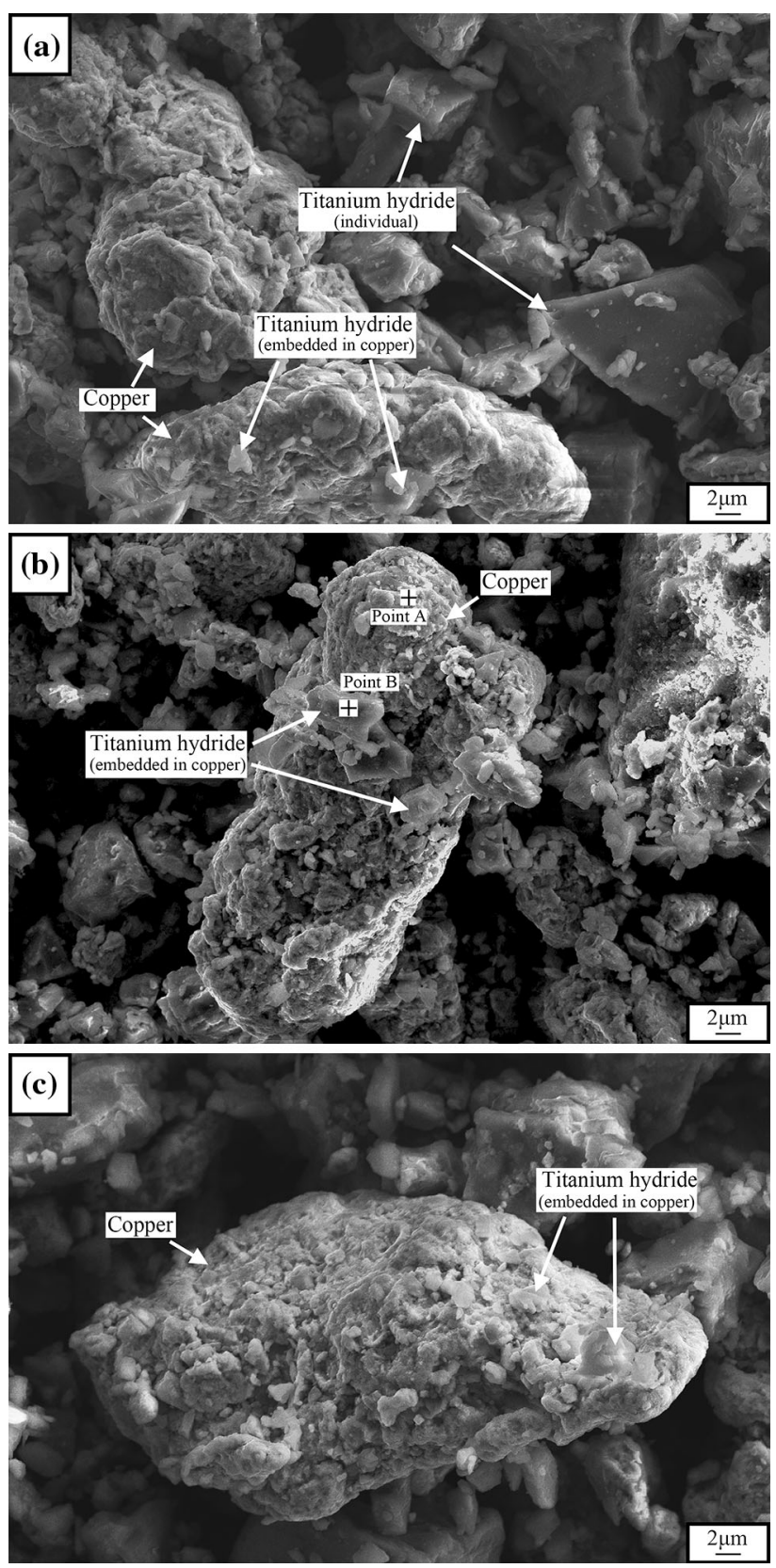

Fig. 4-Morphology of titanium hydride and copper powder mixture after different milling time: (a) $2 \mathrm{~h}$; (b) $4 \mathrm{~h}$; (c) $6 \mathrm{~h}$.

It can be seen from Figure 4 that when milling time was 2 hours, there were still many fractured titanium hydride particles which existed individually and were not embedded in copper matrix. When the time was extended to 4 hours, most of the titanium hydride particles were embedded in copper matrix and existed in the form of composite particles. When the time was extended to 6 hours, the morphology of composite particles didn't change obviously. Besides milling time, the influence of weight ratio of titanium hydride powder to copper powder (varies from 1:1 to $1: 2$ and 1:4) on the milling process is also investigated in our study, the results are shown in Figure 6. It can be seen from Figure 6 that the morphology of composite particles didn't change obviously when increasing the amount of copper powder. It is sufficient to get most of the titanium hydride particles embedded in copper matrix when the weight ratio is $1: 1$. Therefore, proper parameters in the ball milling process can be summarized as follows: weight ratio of titanium hydride powder to copper powder was 1:1, weight ratio of ball to powder was $3: 1$, milling rate was $250 \mathrm{r} / \mathrm{min}$ and milling time was 4 hours. When titanium hydride is ball milled with copper powder by these parameters before adding to the melt, an uniform pore structure with small pore size can be obtained (see Figure 1(c) through (f)).

Figure 7 shows the XRD results of titanium hydride before and after pre-oxidation treatment and ball milling process. The diffraction pattern of as-received titanium hydride matches with $\mathrm{TiH}_{1.924}$ (PDF \#25-0982 of the ICDD database). It belongs to Fm-3m space group in which $\mathrm{Ti}$ atoms form a face-centered cubic structure and hydrogen atoms randomly sit on the tetrahedral sites. ${ }^{[34]}$ After pre-oxidation treatment, peaks of $\mathrm{TiO}_{2}$ and $\mathrm{Ti}_{3} \mathrm{O}$ appear. All the peaks of titanium hydride shift to higher $2 \theta$ values. When such pre-oxidized titanium hydride powder was ball milled with copper powder subsequently, peaks of copper appear and peaks of titanium hydride further shift to higher $2 \theta$ values.

The relation between diffraction angle $\theta$ and interplanar distance $d$ can be described by Bragg's law in Eq. [4], where $\lambda$ is the wavelength of incident wave, $n$ is a positive integer. In face-centered cubic structure, interplanar distance $d$ is determined by the lattice constant $a$ and crystal face indices $(h k l)$, their relation is given in Eq. [5].

$$
\begin{gathered}
2 d \sin \theta=n \lambda \\
d=\frac{a}{\sqrt{h^{2}+k^{2}+l^{2}}}
\end{gathered}
$$

It can be seen from Eq. [4] and [5] that $a \propto d \propto 1 / \sin \theta$, so $a$ decreases with the increase of $\theta$. According to titanium hydride's crystal structure, ${ }^{[34]} a$ is influenced by the amount of hydrogen atoms on the tetrahedral sites, the decrease of $a$ means less hydrogen atoms on the tetrahedral sites. That is to say, the increase of $\theta$ is caused by the decrease of hydrogen atoms in titanium hydride. In the pre-oxidation treatment, besides oxidation, titanium hydride particles also released some hydrogen atoms and changed from 


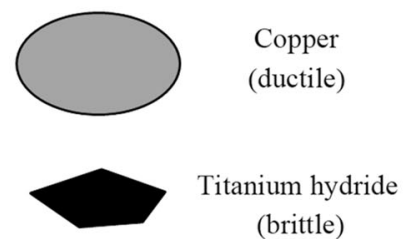

Initial powders

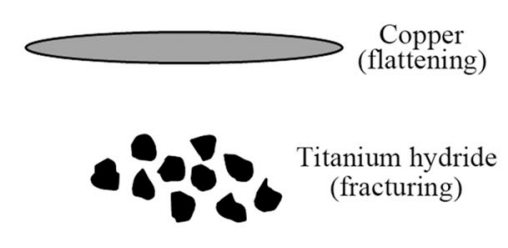

Stage I
Embedding of titanium hydride particles

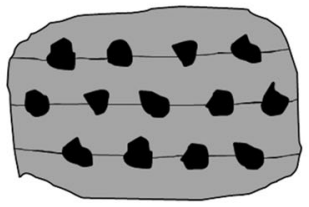

Stage II

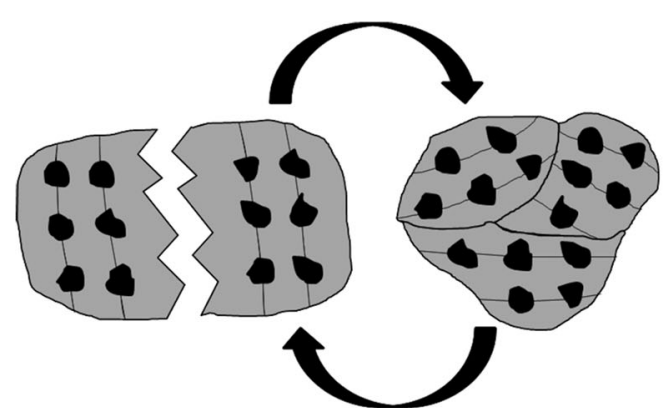

Stage III
Repeated fracturing

and welding process

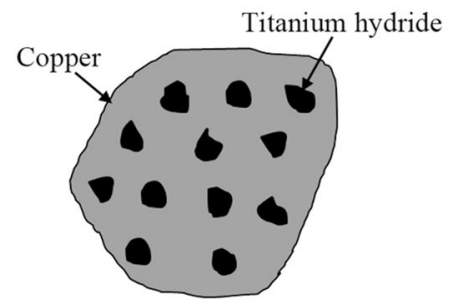

Final composite particle

Fig. 5- Schematic diagram of the morphology changes of titanium hydride and copper particles during ball milling process.

$\mathrm{TiH}_{1.924}$ to $\mathrm{TiH}_{x}$ (Range of $x$ after pre-oxidation treatment: $1.5<x<1.924)$; The increase of $\theta$ after the ball milling process implies that the amount of hydrogen atoms further decreased and the hydride transferred to $\mathrm{TiH}_{x}$ with less hydrogen atoms (Range of $x$ after ball milling: $x<1.5$ ).

On the one hand, a certain amount of hydrogen was released after ball milling. On the other hand, titanium hydride particles were fractured during ball milling process. The oxide layer was inevitably somewhat damaged and the fractured particles with smaller size were more active. Thus more hydrogen was released and burnt out during the dispersion stage. These two reasons lead to the decrease of the amount of hydrogen released in the foaming stage. So the porosity will decrease correspondingly, which also contributes to the decrease of pore size.

It should be noted that after ball milling, the delay of decomposition provided by pre-oxidation was just partly weakened and still existed. In addition, when titanium hydride was added in the form of composite particles, due to the higher melting point of copper and the kinetics of its diffusion into aluminum melt, it remained in solid state for a certain time. Thus it can act as a diffusion barrier and delayed the decomposition of titanium hydride particles embedded in it. So, the time for dispersion is still sufficient and a uniform pore structure could be obtained.

Although decreasing the amount of titanium hydride addition can also decrease the porosity and pore size, it doesn't solve the wettability problem and the difficulty of titanium hydride's dispersion in the melt isn't reduced, either. In addition, the number of titanium hydride particles is also decreased correspondingly. So, under the same porosity condition, the pore size can't decrease to the same value compared to aluminum foams fabricated by using titanium hydride in milled form (see Table III). 

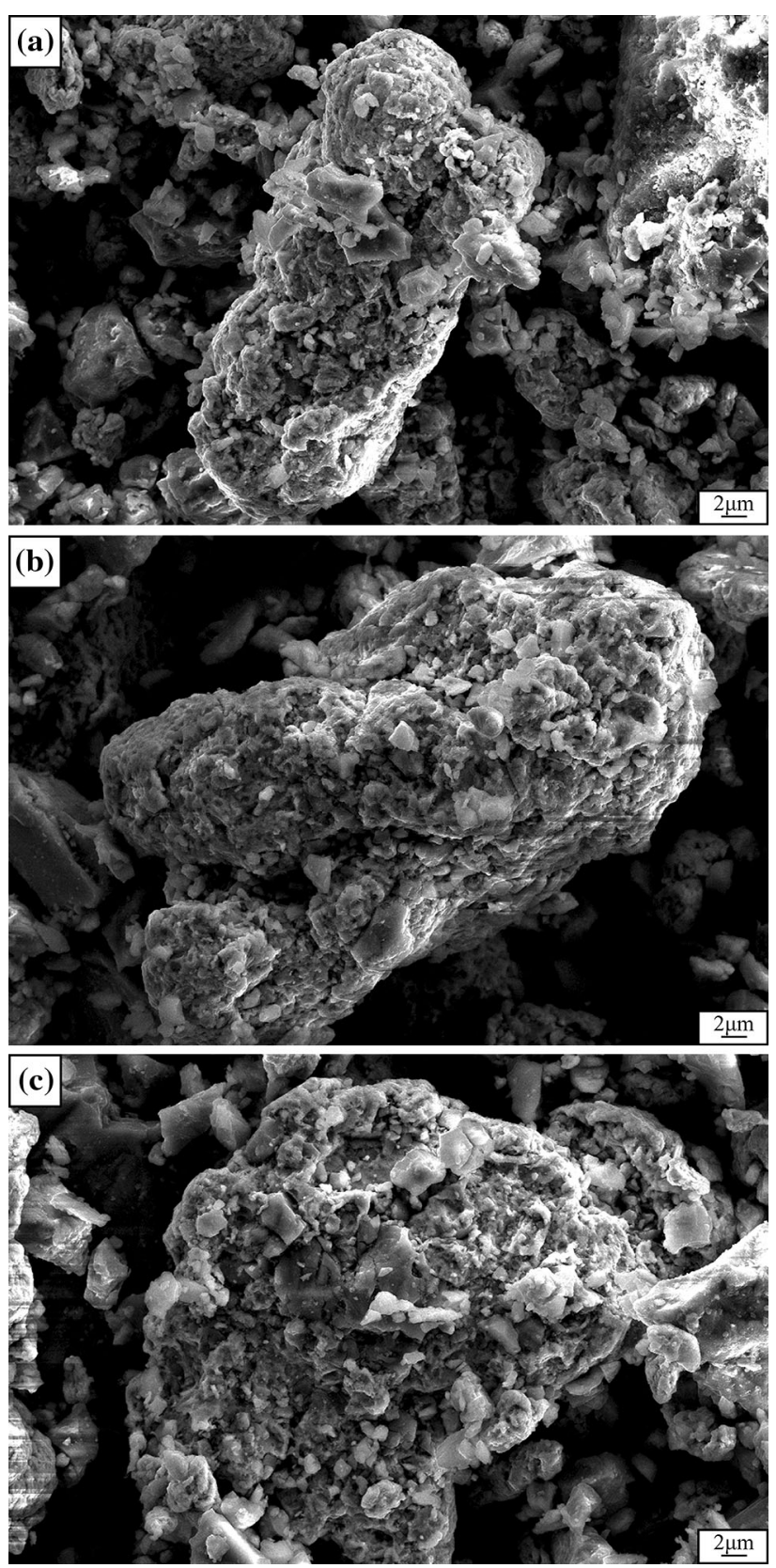

Fig. 6-Morphology of titanium hydride and copper powder mixture with different weight ratio of titanium hydride powder to copper powder: (a) $1: 1 ;(b) 1: 2 ;(c) 1: 4$.

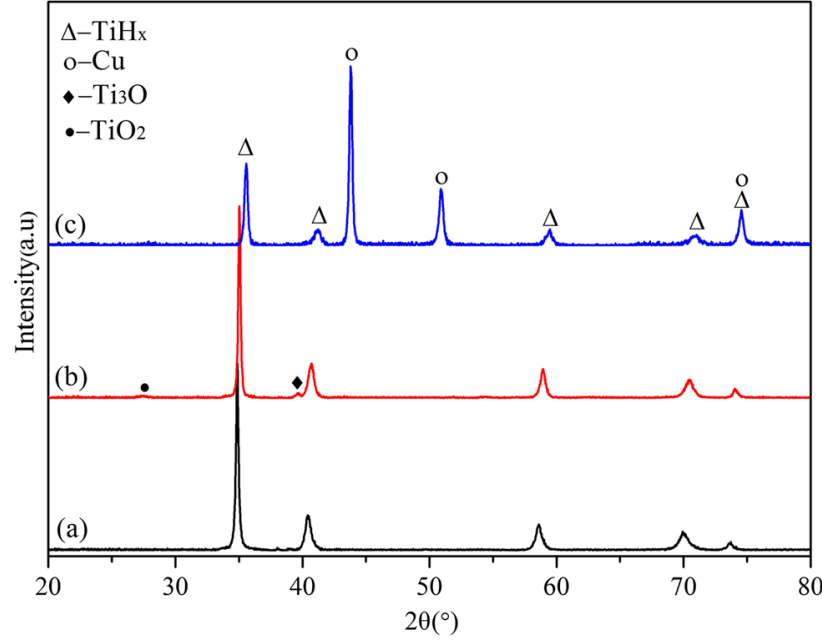

Fig. 7-XRD patterns of titanium hydride: $(a)$ as-received; $(b)$ after preheating in air; $(c)$ after ball milling with copper powder.

\section{CONCLUSIONS}

In summarize, aluminum foams with small pore size can be obtained by introducing ball milling in the pretreatment process of titanium hydride. Reasons are as follows: after ball milled with copper powder, titanium hydride particles are fractured and thus the number of particles will increase. The fractured titanium hydride particles are pre-dispersed in the copper matrix whose wettability with aluminum is good, which makes titanium hydride particles easier to disperse in the aluminum melt with less aggregation. In addition, the amount of hydrogen released in the foaming stage is reduced. All these improvements contribute to the decrease of pore size.

\section{ACKNOWLEDGMENT}

This work was supported by National Natural Science Foundations (No. 51371104).

\section{REFERENCES}

1. M. Mukherjee, F. Garcia-Moreno, and J. Banhart: Metall. Mater. Trans. B, 2010, vol. 41B, pp. 500-04. 
2. A.G. Evans, J.W. Hutchinson, and M.F. Ashby: Prog. Mater. Sci., 1999, vol. 43, pp. 171-221.

3. D.X. Sun and Y.Y. Zhao: Metall. Mater. Trans. B, 2003, vol. 34B, pp. 69-74.

4. Y. Wen-Wen, L. Yan-Xiang, and C. Xiang: Chin. J. Nonferrous Metall, 2011, vol. 21 (1), pp. 138-44.

5. X. Zhu, S. Ai, X. Ling, L. Zhu, and B. Liu: Int. J. Heat Mass Transf., 2014, vol. 72, pp. 242-49.

6. Z. Xu and H. Hao: J. Alloys Compd., 2014, vol. 617, pp. 207-13.

7. J. Banhart: Prog. Mater. Sci., 2001, vol. 46, pp. 559-632.

8. J. Banhart: Adv. Eng. Mater., 2013, vol. 15 (3), pp. 82-111.

9. A. Soloki and M. Esmailian: Metall. Mater. Trans. B, 2015, vol. 46B, pp. 1052-57.

10. T. Miyoshi, M. Itoh, S. Akiyama, and A. Kitahara: Adv. Eng. Mater., 2000, vol. 2 (4), pp. 179-83.

11. L. Yanxiang: Spec. Cast. Nonferrous Alloys, 2011, vol. 31 (12), pp. 1097-99.

12. Y. Wenwen, C. Xiang, L. Yuan, and L. Yanxiang: Rare Metall. Mater. Eng., 2009, vol. 38 (suppl. 3), pp. 306-10.

13. N. Babcsan, S. Beke, P. Makk, G. Szamel, and C. Kadar: Proc. Mater. Sci., 2014, vol. 4, pp. 127-32.

14. N. Babcsan, S. Beke, G. Szamel, T. Borzsonyi, B. Szabo, R. Mokso, C. Kadar, and J.B. Kiss: Proc. Mater. Sci., 2014, vol. 4, pp. 69-74.

15. Z. Yi, H. Deping, and J. Jiaqiao: Sci. China Ser. B Chem., 2004, vol. 47 (5), pp. 407-13.

16. Z. Xiaoqing, A.R. Kennedy, W. Yongsheng, B. Yushun, L. Jiansheng, and Z. Yun: Rare Met Mater. Eng., 2009, vol. 38 (suppl. 3), pp. 254-59.

17. Y. Dong-Hui and H. De-Ping: Chin. J. Nonferrous Met., 2004, vol. 14 (12), pp. 2021-28.

18. G. Wang-Yi, H. Si-Yuan, H. De-Ping, Z. Yong-Ming, W. Lian-Feng, and T. Dao-Chi: Mater Mech. Eng., 2010, vol. 34 (1), pp. 45-48.
19. J. Hartmann, A. Trepper, and C. Körner: Adv. Eng. Mater., 2011, vol. 13 (11), pp. 1050-55.

20. J. Hartmann, C. Blümel, S. Ernst, T. Fiegl, K.-E. Wirth, and C. Körner: J. Mater. Sci., 2014, vol. 49, pp. 79-87.

21. B. Matijasevic-Lux, J. Banhart, S. Fiechter, O. Görke, and N. Wanderka: Acta Mater., 2006, vol. 54, pp. 1887-1900.

22. H.-J. Luo, H. Lin, P.-H. Chen, and G.-C. Yao: Rare Met., 2015, vol. 34 (1), pp. 28-33.

23. Z. Song and S.R. Nutt: Mater. Sci. Eng. A, 2007, vol. 458, pp. $108-15$

24. R. Soltani, Z. Sarajan, and M. Soltani: Mater. Res. Innov., 2014, vol. 18 (6), pp. 401-06.

25. C.C. Yang and H. Nakae: J. Mater. Process. Technol., 2003, vol. 141, pp. 202-06.

26. L. Peisheng: Titan. Ind. Prog., 2006, vol. 23 (2), pp. 29-34.

27. C. Körner: Integral Foam Molding of Light Metals-Technology, Foam Physics and Foam Simulation, Springer, Berlin, 2008, pp. $63-$ 64.

28. L. Da-Wu, S. Ting, Y. Guang-Chun, Z. Xiao-Ming, and L. Jie: Chin. J. Nonferrous Metall., 2010, vol. 20 (1), pp. 143-48.

29. S. Tahamtan, A. Halvaee, M. Emamy, and M.S. Zabihi: Mater. Des., 2013, vol. 49, pp. 347-59.

30. Z. Zhang, J. Ding, X. Xia, X. Sun, K. Song, W. Zhao, and B. Liao: Mater. Des., 2015, vol. 88, pp. 359-65.

31. C.A. León, G. Mendoza-Suarez, and R.A.L. Drew: J. Mater. Sci., 2006, vol. 41, pp. 5081-87.

32. L. Huang, H. Wang, D.H. Yang, F. Ye, S.Q. Wang, and Z.P. Lu: Mater. Sci. Eng. A, 2014, vol. 618, pp. 471-78.

33. C. Suryanarayana: Prog. Mater. Sci., 2001, vol. 46, pp. 1-184.

34. C. Jiménez, F. Garcia-Moreno, B. Pfretzschner, M. Klaus, M. Wollgarten, I. Zizak, G. Schumacher, M. Tovar, and J. Banhart: Acta Mater., 2011, vol. 59, pp. 6318-6. 